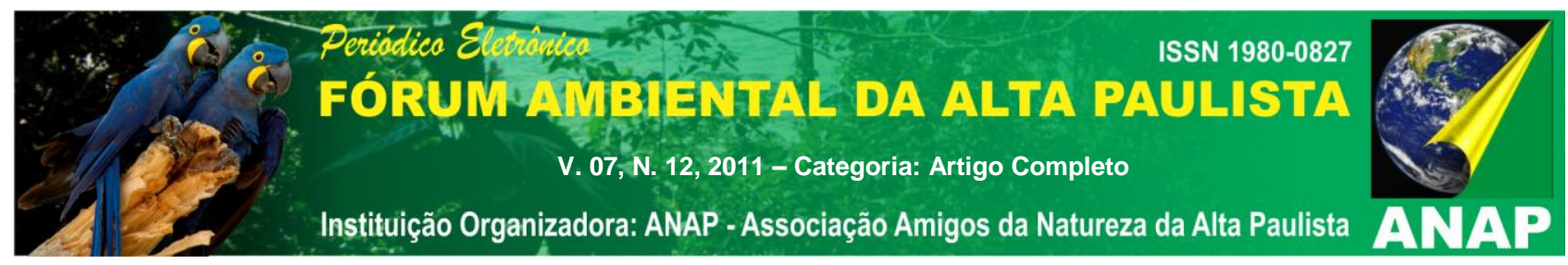

\title{
PERCEPÇÃO DAS MOSCAS PELOS MORADORES DO BAIRRO JARDIM MORADA DO SOL, PRESIDENTE PRUDENTE, SÃO PAULO
}

\author{
Eduardo Lira da Silva ${ }^{1}$ \\ Leonice Seolin Dias ${ }^{2}$ \\ Raul Borges Guimarães ${ }^{3}$
}

\begin{abstract}
Resumo: Algumas espécies de moscas são causadoras de doenças. Além disso, esses insetos convivem diariamente com os homens e animais domésticos. Para melhor compreender a percepção que a população do bairro Morada do Sol do município de Presidente Prudente, São Paulo, tem sobre esses insetos, no período de entre dezembro de 2010 a fevereiro de 2011, foram aplicados 200 questionários aos moradores. A maioria dos residentes do bairro é de ex-catadores de lixo e vive em condições precárias, pois o local é considerado um dos mais carentes da cidade. Do total de entrevistados, $70 \%$ são mulheres e $30 \%$ homens. Com base nas informações registradas na comunidade com respeito à identificação dos tipos de moscas, 190 moradores citaram os membros da família Calliphoridae, 93 da Muscidae e 38 da Tabanidae. Quando vêem uma mosca, 162 dos moradores dizem ter nojo, 107 associam à sujeira e 102 sentem o desejo de matar. Do total de entrevistados, 169 acreditam que utilizando veneno podem eliminar as moscas, 53 que, por meio da limpeza e sete tem que realizar limpeza nos terrenos baldios. Apenas um entrevistado não acredita na eliminação das moscas. Compreender a construção que a sociedade faz sobre esses insetos pode contribuir para a maneira como os indivíduos elaboram seu convívio com situações de risco e pode ajudar a melhorar a saúde pública.
\end{abstract}

Palavras-chave: Geografia da saúde, percepção do risco, moscas.

\section{INTRODUÇÃO}

\footnotetext{
${ }^{1}$ Eduardo Lira da Silva - peixotobatista@hotmail.com

Graduando do curso de Geografia pela Universidade Estadual Paulista - UNESP, Presidente Prudente SP.

2 Leonice Seolin Dias - nseolin@gmail.com

Mestre, colaboradora do Laboratório de Geografia da Saúde da UNESP, Presidente Prudente - SP.

${ }^{3}$ Raul Borges Guimarães - raul@fct.unesp.br

Professor Adjunto (Livre Docente) do Departamento de Geografia e Coordenador do Laboratório de Geografia da Saúde da UNESP, Presidente Prudente - SP.
} 


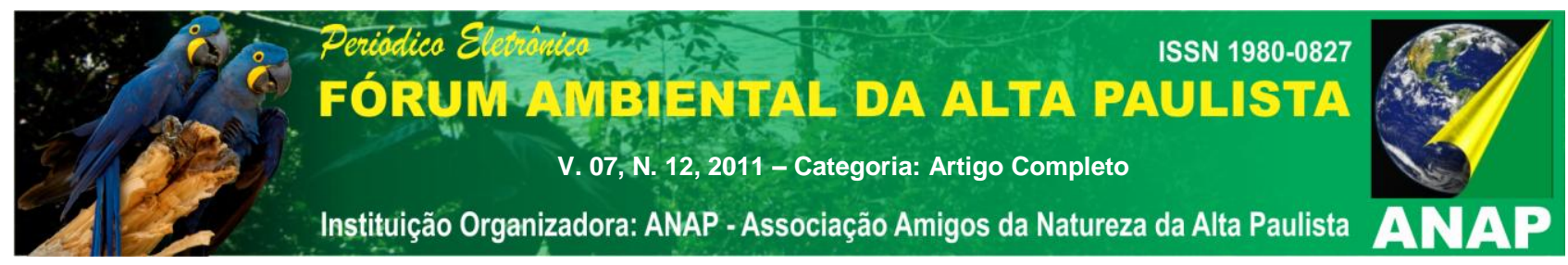

\section{As moscas no Reino Animal}

Os insetos representam cerca de $80 \%$ de todas as espécies de animais catalogadas em todo mundo. A classe Insecta consta com mais de 750.000 espécies conhecidas atualmente. Além disso, milhares de novas espécies são descritas anualmente, estimandose que 2-5 milhões de espécies estão esperando por uma descrição.

Atualmente existem 31 ordens de insetos já catalogadas. Destas, quatro são descritas como sendo hiperdiversas, sendo uma delas a Ordem Díptera (com cerca de 150.000 espécies), que é representada pelos mosquitos e moscas (LARA, 1977; AMORIM et al, 2002).

\section{O que é uma mosca?}

As moscas apresentam o corpo dividido em três regiões distintas, a cabeça, o tórax e o abdômen, que é revestido por um esqueleto externo rígido (exoesqueleto). A cabeça contém um par de antenas, um de olhos compostos e três simples ou ocelos. $O$ aparelho bucal pode variar muito, porém são fundamentalmente sugadores. As moscas adultas sugadoras alimentam-se de substâncias líquidas ou que estão em fase de liquefação como, por exemplo, fezes, animais e vegetais em decomposição entre outras coisas. As substâncias líquidas são ingeridas diretamente, já as substâncias sólidas são dissolvidas com o auxílio da saliva e com um líquido regurgitado do tubo digestivo.

O tórax é formado de três segmentos (protórax, o mesotórax e o metatórax), tendo em cada um deles um par de pernas articuladas e, em geral, um par de asas mesotorácicas funcionais, o par posterior reduzido a uma estrutura em forma de halter ou balancim.

Por último, o abdômen é constituído por segmentos em número nunca menos que cinco nem mais que doze, e onde se encontram alojados as vísceras e as estruturas associadas à função reprodutora (Figura 1) (CARRERA, 1963; LARA 1977; FORANTIN, MACLEAD, DONNELLY, 1957; PAIVA, 1994). 

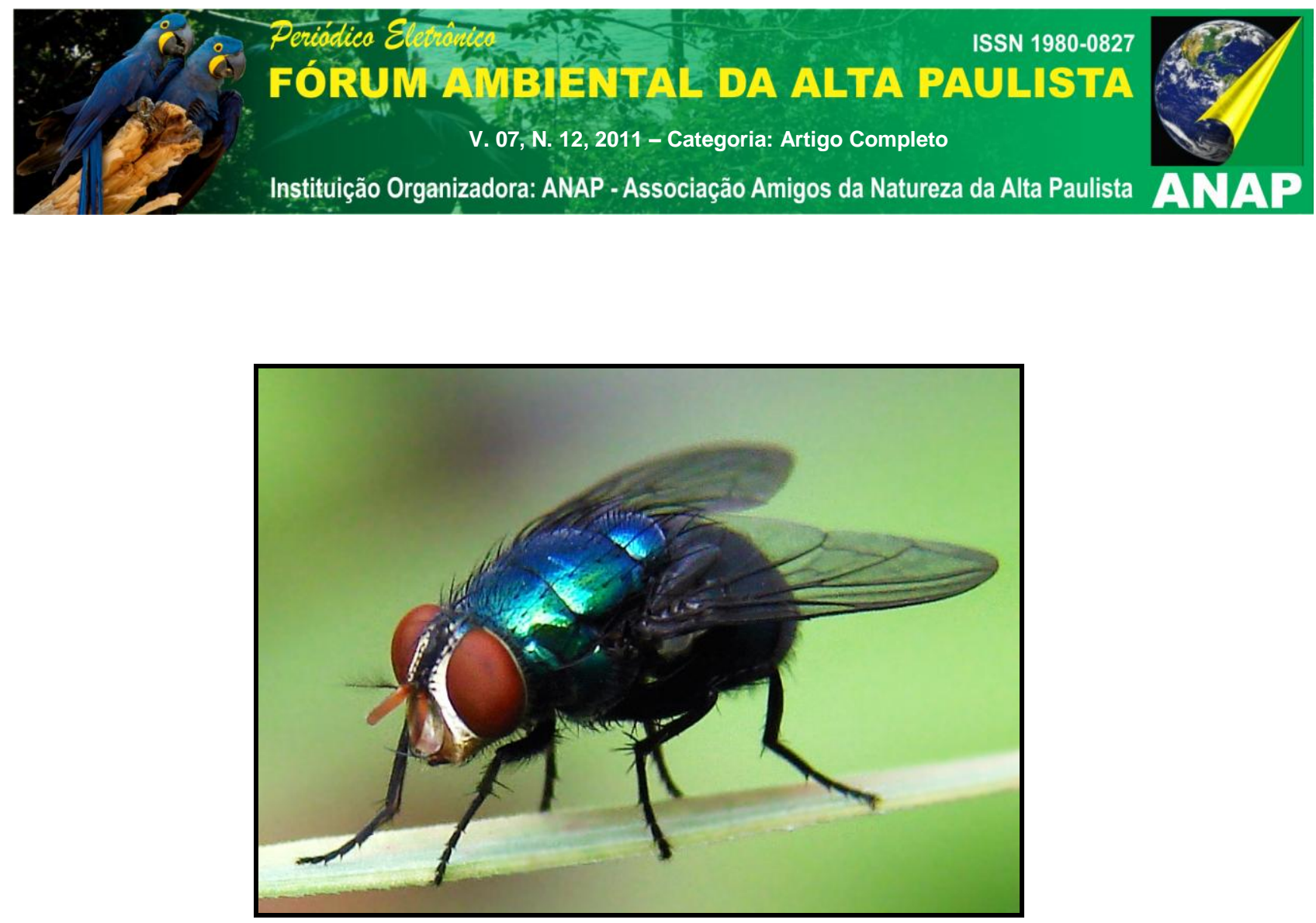

Figura 1. Mosca pertencente à família varejeira.

Fonte: http://olhares.uol.com.br/serie_mosca_varejeira_1_foto1261607.html

\section{Ciclo biológico}

As moscas apresentam metamorfose completa: ovo, larva, pupa e adulto. As fases de desenvolvimento desses insetos requerem de oito a 20 dias no verão, e a desova da fêmea inicia quatro a 20 dias após tornar-se adulta. As fêmeas adultas depositam seus ovos, de aproximadamente de $01 \mathrm{~mm}$ de comprimento, em lotes de 75 a 150 ovos, em cinco a sete posturas, totalizando 500 a 900 ovos durante o ciclo de vida. Elas depositam seus ovos em carcaças de animais, fossas abertas, terrenos baldios, fezes de animais, depósitos de lixo, e outros locais ricos em matéria orgânica de origem vegetal e/ou animal em decomposição.

O tempo necessário para completar o ciclo de vida das moscas depende da espécie a que pertence e das condições ambientais, sobre tudo a temperatura (MINKIN, SCOTT, 1960; SOULSBY, 1982; PAIVA, 1994; PRADO, 2003).

\section{Principais famílias de moscas de importância para saúde}




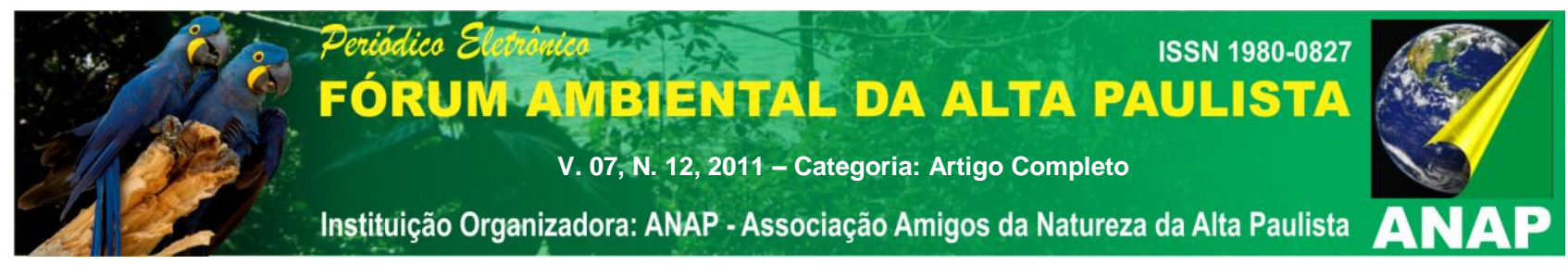

Dentre as espécies de insetos dípteros, somente cerca de 20 delas estão mais intimamente associadas ao homem nas áreas urbanas, distribuídas por 10 famílias, sendo as mais importantes às famílias Caliphoridae, Fanniidae, Muscidae e Sarcophagidae (PRADO, 2003). Essas famílias possuem espécies sinantrópicas, devido ao seu alto grau de associação com o homem, que ocorre pelo fato de as moscas serem exploradores de substâncias e dejetos produzidos pela atividade humana e animal (LINHARES, 1979; MONTEIRO, 1995).

Os membros dessas famílias podem ser considerados como uma das mais importantes pragas em ambientes urbanos atualmente, com implicações para a saúde humana e de animais domésticos, uma vez que muitas espécies podem veicular mecanicamente inúmeros patógenos (GREENBERG, 1971). Dessa forma, Mariconi, Guimarães e Filho (1999) afirmam que esses insetos despertam grande importância médico-sanitária, uma vez que sua ocorrência, distribuição e predominância em áreas metropolitanas são fatores de grande importância em saúde pública.

\section{Os estudos sobre moscas realizados no Laboratório de Geografia da Saúde do CEMESPP}

O CEMESPP (Centro de Estudos e Mapeamento da Exclusão Social para Políticas Públicas) é um grupo interdepartamental da FCT/UNESP na interface da Geografia, Planejamento Urbano, Saúde Pública e Coletiva, Educação e Estatística Espacial. Para a realização de estudos na linha de pesquisa "Ambiente e Saúde", o CEMESPP possui o Laboratório de Geografia da Saúde, que se interessa por problemas ligados à qualidade de vida e de questões diretamente relacionadas a aspectos, tais como: poluição do ar, poluição da água, enchentes, resíduos sólidos, epidemias, etc.

A partir destas preocupações, o laboratório vem desenvolvendo pesquisas sobre a população de dípteros, uma vez que dentre os insetos que se adaptaram ao ambiente construído pelo homem destacam-se as moscas, pela sua diversidade de espécies, abundância populacional, o curto ciclo reprodutivo e a dificuldade de controle. A importância epidemiológica das moscas se deve ao fato de serem agentes patogênicos, tanto de vírus como de fungos, bactérias, protozoários e helmintos. Por tudo isso, verificase uma grande relevância de estudos dessa natureza. 


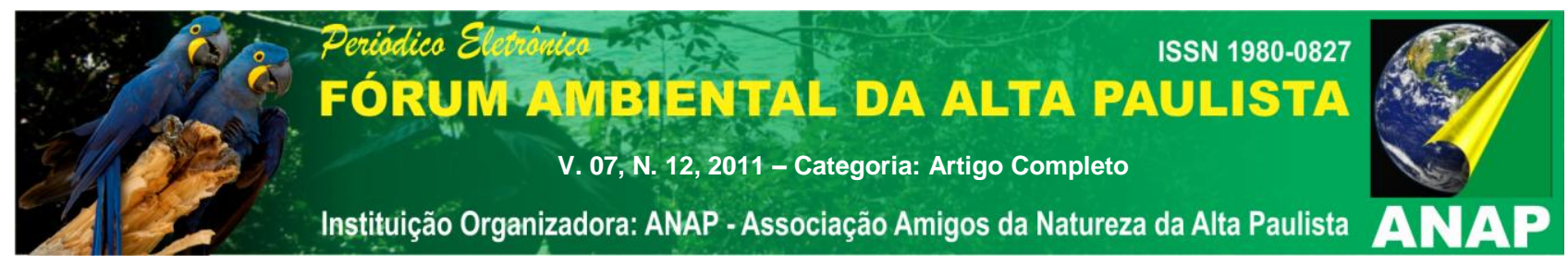

\section{A metodologia do estudo da percepção do risco}

O objetivo do presente trabalho é de analisar a percepção que a população tem a respeito das moscas existentes em seus locais de residência. Por que isto é importante? Já que as moscas são animais que estão diretamente interagindo com as pessoas, convivendo dia-a-dia, principalmente, no ambiente caseiro e, paralelo a isto, são transmissores de diversas doenças. Logo é uma questão de saúde pública compreender o entendimento que as pessoas fazem sobre estes insetos e, por isso, espera-se aprofundar o conhecimento acerca da maneira como os indivíduos elaboram a sua convivência com situações de risco.

A noção de risco está diretamente ligada ao perigo, instabilidade e vulnerabilidade, esta noção pode nos manifestar mais diversos setores e problemas do dia a dia da sociedade, tanto do local quanto do global. "É por isso alvo de amplas investigações no campo do conhecimento das ciências naturais, através de estudos orientados para as causas e previsão dos fenômenos que lhe estão associados, bem como na área das ciências sociais, relacionados, sobretudo com a percepção e prevenção" (QUEIRÓS; VAZ; PALMA, 2007).

A percepção dos riscos está profundamente inserida às emoções particulares da sociedade e, em sentido mais amplo, no contexto cultural (QUEIRÓS, 2000). Isto significa que as pessoas fazem uma interpretação dos riscos, são agentes que constroem ativamente seu significado no dia a dia, e relacionam o seu pensamento e a sua ação e reação na presença do risco (QUEIRÓs; VAZ; PALMA, 2007).

\section{A percepção das moscas pelos moradores do bairro jardim morada do sol}

O bairro Jardim Morada do Sol, localizado no município de Presidente Prudente no estado de São Paulo, esta situado em uma das regiões mais pobres do município, onde muitas famílias foram colocadas de forma precária, envolvidos em um programa do município de eliminação de favelas (TORREZAN, 2009). O bairro está localizado a sete 


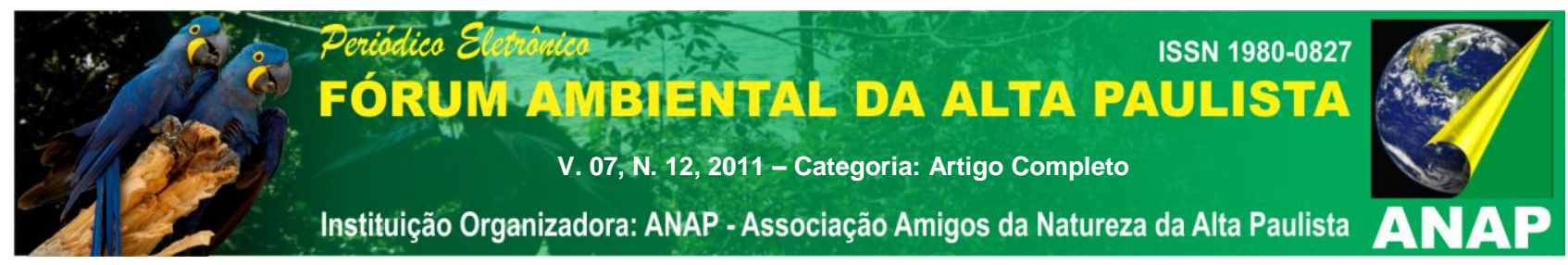

quilômetros da área central, propiciando um sentimento de isolamento por parte dos moradores, e conta com algumas infraestruturas. O nível de exclusão é enorme. Segundo Oliveira (2010), a população desse local, além de não ter a infra-estrutura necessária, não dispõe satisfatoriamente dos meios necessários para usufruir dos espaços públicos da cidade, estando sua difícil mobilidade pela má acessibilidade.

Destacamos que neste bairro foram realizados dois estudos sobre a ocorrência de moscas, sendo o primeiro, no período de 2007 a 2008, quando o local estava em processo de organização da infraestrutura; e, o segundo, no período de 2009 a 2010, após ações educativas e melhorias na infraestrutura da comunidade.

\section{PROCEDIMENTOS METODOLÓGICOS}

A pesquisa de campo foi realizada, nos meses de dezembro de 2010 a fevereiro de 2011, junto aos moradores do bairro Jardim Morada do Sol da cidade de Presidente Prudente, SP.

Para aquisição dos dados foi aplicado um questionário composto por sete perguntas: "1. Cite exemplos de insetos que você conheça?", "2. Por que você acha que esses animais (que você exemplificou) são insetos?", "3. Qual a importância dos insetos?", "4. Você acha que ficou doente por causa de algum inseto? Qual doença? Como você sabe disso?", "5. Quando você vê uma mosca, quais as três palavras, que surgem em sua mente?", "6. Quais os tipos de moscas que você conhece?" e "7. O que você acha que deve ser feito para eliminar as moscas?"

O propósito deste trabalho será com ênfase na percepção das moscas pela população do bairro Morada do Sol. Para este propósito foi aplicado 200 questionários com moradores acima de 18 anos.

Os dados foram tratados de forma qualitativa. Destacamos que não houve dificuldades para a realização do trabalho, já que todos os entrevistados se mostraram 


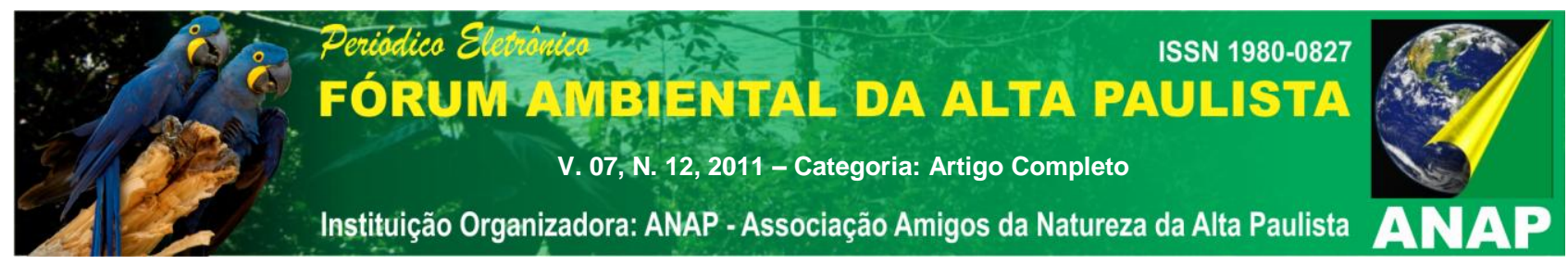

bastante receptivos, interessados em responder as perguntas, muitos encararam com certo humor, acharam graça quando perceberam que as questões tratavam de insetos.

Os questionários encontram-se depositados no Laboratório de Geografia da Saúde da FCT/UNESP de Presidente Prudente para fins de comprovação.

\section{RESULTADOS}

Foram respondidos pelos moradores todos os 200 questionários, sendo $30 \%$ homens e $70 \%$ mulheres.

Com relação à pergunta "Quando você vê uma mosca quais as três palavras, que surgem em sua mente?", os resultados obtidos foram: nojo/nojento com 81\% (162), sujeira/imundice com 53,5\% (107) e matar 51\% (102).

Para a pergunta "Quais os tipos de moscas que você conhece?", as seguintes respostas: Moscas da família Calliphoridae com 190 citações (varejeira = 126, mosca azul= 32, mosca verde $=31$ e mosca do lixo =01), moscas da família Muscidae com 93 ( mosca preta $=55$, mosca comum $=23$ e mosquito $=15)$ e moscas da família Tabanidae com 38 (mutuca $=37$ e mosca do cavalo $=01$ ). Foram citados também três insetos associados à mosca, sendo pernilongo por um morador e o dengue por dois.

Para a pergunta "O que você acha que deve ser feito para eliminar as moscas?", as respostas foram: veneno com $84,5 \%$ (169), higiene/limpeza com 26,5\% (53) e acabar com terrenos baldios 3,5\% (07). Apenas um entrevistado disse que nada poderia ser feito para acabar com as moscas.

\section{CONSIDERAÇÕES FINAIS}

Para compreender melhor a percepção do risco, estudos desta natureza são de extrema importância, uma vez que o objeto da pesquisa são insetos sinantrópicos, ou seja, aqueles que dividem o mesmo espaço com as pessoas e, além disso, são agentes patogênicos, transmissores de inúmeras doenças, como por exemplo, cólera, disenteria infantil, entre outras. Esta relação esta inserida na cultura da sociedade e, por isto, é entendida como uma coisa natural, sem grandes riscos. Logo, compreender a construção 


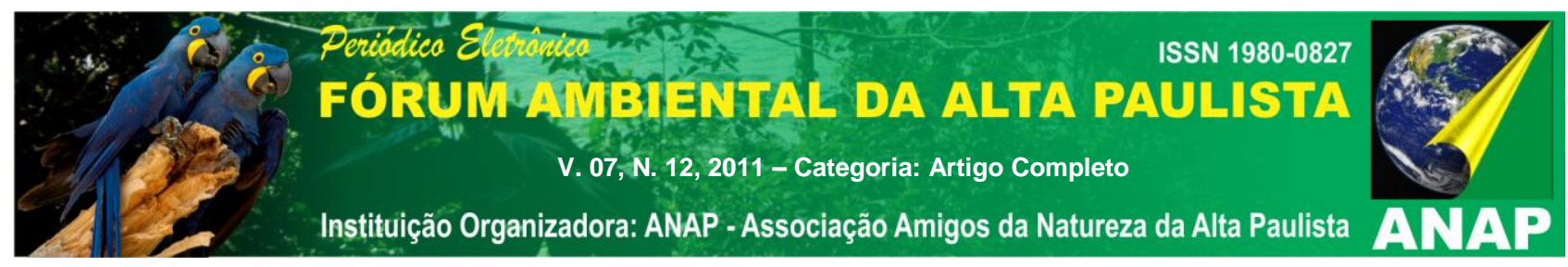

que a sociedade faz sobre esses insetos pode contribuir para a maneira como os indivíduos elaboram seu convívio com situações de risco e pode ajudar a melhorar a saúde pública.

\section{REFERÊNCIAS}

AMORIM, D.S.; SILVA, V.C.; BALBI, M.I.P.A. Estado do Conhecimento dos Díptera Neotropicais. In: COSTA, C.; S.A. VANIN; LOBO, J.M.; MELIC. (Org.). Proyecto de Red Iberoamericana de Biogeografia y Entomologia Sistemática PRIBES 2002. Zaragoza: Sociedad Entomelógica Aragoneza y CYTED, 2002, v. , p. 29-36.

CARRERA, M. Entomologia para você. 2. ed. São Paulo: Universidade de São Paulo, 1963. 217 p.

FORATTINI, O. P. Entomologia Médica. 1. ed. São Paulo, Universidade de São Paulo, 1962.

GREENBERG, B. Flies and disease - ecology, classification and biotic association. New Jersey: Princeton University, 1971. 856 p.

LARA, F. M. Princípios de Entomologia. São Paulo: Universidade Estadual Paulista, 1977.

LINHARES, A. X. Sinantropia de dípteros muscóides de Campinas. 1979. $129 \mathrm{f}$.

Dissertação (Mestrado em Ecologia), Universidade Estadual de Campinas, Campinas.

MACLEAD, J.; DONNELLY, J. Individual and group marking methods for flypopulation studies. Bulletin of Entomological Research, v. 48, p 558- 592, 1957.

MARICONI, F. A. M.; GUIMARÃES, J. H.; BERTI FILHO, E. A mosca doméstica e algumas outras moscas nocivas. Piracicaba: FEALQ, 1999. 135 p.

MINKIN, J. S.; SCOTT, H. G. House fly pupation under baseboards. Journal of Economic Entomology, v. 53, p. 479-480, 1960.

MONTEIRO, R. M. Microhimenópteros (Insecta: Hymenoptera) parasitóides e insetos predadores de moscas sinantrópicas (Insecta: Diptera) na Granja Capuavinha, Monte-Mor, SP. 1995. 99 f. Dissertação de mestrado, UNICAMP, Campinas.

OLIVEIRA, V. F. Acessibilidade e mobilidade urbana: uma análise socioespacial a partir dos bairros Jardim Morada do Sol e Conjunto Habitacional Ana Jacinta, em Presidente Prudente. In: XVI ENCONTRO NACIONAL DE GEÓGRAFOS - Crise, práxis e autonomia: espaços de resistência e de esperanças, 2010, Porto Alegre. Disponível em: <www.agb.org.br/evento/download.php?idTrabalho=1965>. Acesso em: maio de 2011.

PAIVA, D. P. Controle integrado de moscas em criações de suínos. Suinocultura Dinâmica, Concórdia, SC, n.12, p. 1-5, 1994. 


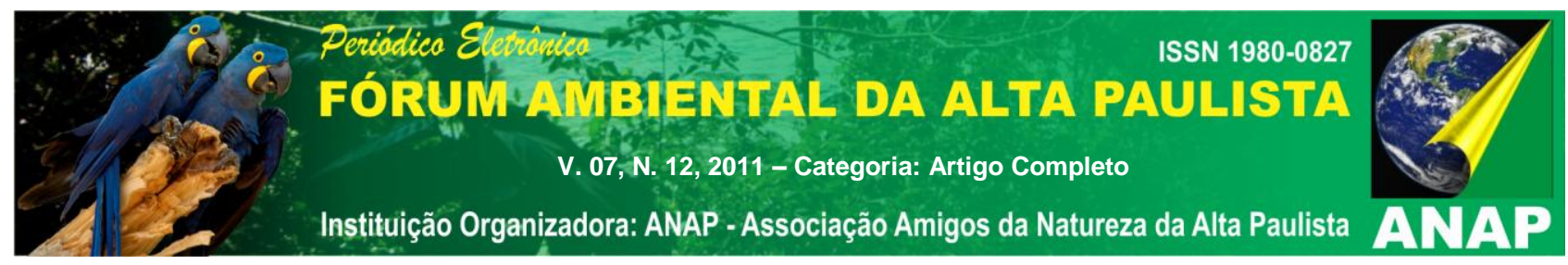

PRADO, A. P. Controle das principais espécies de moscas em áreas urbanas. Biológico, v. 65, p. 95-97, 2003.

QUEIRÓS, M. Uma reflexão sobre as perspectivas metodológicas na análise do risco ambiental, Actas do Colóquio Geografia dos Riscos, Planigeo, FLUL, Lisboa, p. 80 92, 2000.

QUEIRÓS, M.; VAZ, T.; PALMA, P. Uma Reflexão a Propósito do Risco. Congresso da Geografia Portuguesa "Pensar e Intervir no Território Uma Geografia para o Desenvolvimento". Associação Portuguesa de Geógrafos, 2007, Lisboa. Anais...VI Congresso da Geografia Portuguesa, 2007.

SEOLIN DIAS, L.; GUIMARÃES, R. B. Ocorrência de Dípteros Muscóides no Jardim Morada do Sol, no Município de Presidente Prudente, São Paulo, Brasil. Fórum Ambiental da Alta Paulista, v. V, p. 1303-1309, 2009.

SOULSBY, E. J. L. Helminths, arthropods and protozoa of domesticated animals. 7.ed. London: Baillière Tindall, 1982. p. 343-344.

TORREZAN, R. M. Problematização da Saúde Pública e Educação Educativa nas Comunidades do Jardim Morada do Sol e Parque Residencial Francisco Belo Galindo (Presidente Prudente/ SP). 2009. 136 f. Dissertação (Mestrado em Ciências Humanas) - FCT/UNESP, Presidente Prudente. 